Tropical Agricultural Pesearch \& Extension 21 (3 \& 4): 2018

\title{
MATING DISRUPTION OF Cadra cautella IN THE PRESENCE OF SYNTHETIC SEX PHEROMONE (Z, E)-9, 12-TETRADECADIENYL ACETATE (ZETA)
}

\author{
Sammani AMP, Dissanayaka DMSK, Wijayaratne LKW*, Egodawatta WCP \\ Department of Plant Sciences, Faculty of Agriculture, Rajarata University of Sri Lanka, \\ Puliyankulama, Anuradhapura, Sri Lanka
}

\begin{abstract}
The almond moth Cadra cautella (Walk.) (Lepidoptera: Pyralidae) is difficult to control using insecticides. Female moth releases a sex pheromone identified as $(Z, E)-9$, 12-tetradecadienyl acetate (ZETA). Information on population management of $C$. cautella using pheromone is limited. Objectives of this study were to determine the effect of pheromone dose, population size and air flow on mating status of $C$. cautella. The unmated male and female adults were introduced into a cubicle, allowed mating, recaptured, and the females dissected to determine the presence of spermatophores indicative of mating. The moths exposed to pheromone doses had lower mating than untreated control. Mating disruption (MD) was higher at ZETA $4.5 \mathrm{mg} / 45 \mathrm{~mL}$ than other doses. For each population size tested, moths exposed to synthetic pheromone had lower mating than their respective control. Insect population sizes 10 and 20 had higher MD with the natural air flow than 30 moths $/ 3.375 \mathrm{~m}^{3}$. In contrast, under forced air flow, MD was similar across all the population sizes tested. This study reveals that MD using ZETA is possible for controlling $C$. cautella. Future research should address its usage under warehouse conditions having different complexities.
\end{abstract}

Keywords: Air movement, Cadra cautella, Mating disruption, Pheromone dose, Population size

\section{INTRODUCTION}

Loss of durable food commodities including cereals, pulses and nuts continues when the yield is stored following harvest to cater the consumer demand at different spatial and temporal profiles. Numerous quantitative and qualitative losses caused by living organisms including insects in raw and processed commodities during different post-harvest operations impose a great challenge for food security (Hill, 1990; Hagstrum and Subramanyam, 2006). Stored-product insects cause 10\%-50\% direct and indirect losses of grains and grainbased products throughout the world (Wijayaratne et al., 2018). In Sri Lanka, 80\% of grain loss during storage is caused by insects (Wijayaratne et al., 2009). The Almond *Corresponding author: wollylk@yahoo.com moth Cadra cautella (Lepidoptera: Pyralidae) is a major pest of stored products throughout the warmer parts of the world and in heated stores in temperate regions. The larvae feed on grains, flour, nuts, dried fruits, seeds and other food products causing economic loss (Hill, 1990).

The current control methods for storedproduct pests include the use of contact insecticide Pyrethroids (Ghimire et al., 2016) and fumigation with phosphine (Ridley et al., 2011) or sulfuryl fluoride (Fields, 2012). However, resistance development by certain stored-product insect species (Arthur et al., 1988; Opit et al., 2012), adverse effects on non-target organisms and environment (Fields, 1992; Arthur, 1996; Phillips and 
Throne, 2010; Wijayaratne et al., 2018) impose limitations for the continuous use of synthetic chemical insecticides. Alternatives include use of high (Brijwani et al., 2012) or low temperature (Eliopoulos et al., 2010), hermetic storage (Sanon et al., 2011; Hasaranga et al., 2018; Wijayaratne et al., 2019), modified atmosphere control (Wijayaratne et al., 2009), botanicals (Dissanayaka et al., 2018b), use of safer insecticides alone or in combination with other management practices (Wijayaratne and Fields, 2010; Wijayaratne et al., 2012a,b; Wijayaratne and Rajapakse, 2018; Wijayaratne et al., 2018). Besides, biorational pest management is emphasized in stored product protection (Phillips and Throne, 2010) as alternative to synthetic chemicals.

Pheromones have been identified from over 35 species of stored-product insects. Pheromones, low-molecular-weight volatile organic compounds released by insects, are used in intraspecific communication. These compounds can be used as attractants in traps for detecting and monitoring pests in storage facilities (Phillips, 1997). There is a renewed interest on the use of pheromones in stored-product protection (Burks and Kuenen, 2012; Trematerra, 2012; Campos and Phillips, 2014; Dissanayaka et al., 2018a). The female $C$. cautella adult moth releases a sex pheromone complex including three compounds (Z, E)-9, 12-tetradecadienyl acetate (ZETA), (Z)-9-tetradecadien-1-yl acetate (ZTA) and (Z, E)-9, 12-tetradecadien-1-ol $(\mathrm{ZETOH})$ to attract the males for mating (Kuwahara et al., 1971; Kuwahara and Casida, 1973; Brady, 1973) and the ratio in the natural pheromone blend is 10:5:1 respectively (Read and Beevor, 1976). ZETA attracts the male insects. The ZTA acts as a synergist for ZETA. ZETOH is an inhibitor of the attraction (Read and Haines, 1976). Response by the male moth is directly proportional to the pheromone releasing rate; high releasing rates simply catch more insects than low rates (Vick et al., 1981). However, the upwind flight of male moths towards ZETA can be disrupted by the availability of high doses of synthetic pheromone. This process is termed mating disruption (MD) (Ryne et al., 2006).

The MD has been successfully used for population management in certain field insects such as the Oriental fruit moth Grapholita molesta (Carde and Minks, 1995) and the pink bollworm Pectinophora gossypiella (Staten et al., 1987). Certain factors affecting the success of MD have been identified: pheromone formula (Evenden et al., 1999), the number and type of dispensers (Sauer and Karg, 1998; Thorpe et al., 1999) and population dynamics of the target species (Carde and Minks 1995). However, MD of many stored-product moths and the effect of factors on its success remain undiscovered. Therefore, the objectives of current study were to determine the effect of ZETA dose, population size and the air movement on the mating status in C. cautella.

\section{MATERIALS AND METHODS Rearing of Almond moth}

C. cautella adults were captured from a rice milling center at Puliyankulama, Anuradhapura, Sri Lanka and reared in the laboratory nearly one year were used in the experiments. The moth adults were introduced to $250 \mathrm{~g}$ of rice flour in plastic bottles ( $1 \mathrm{~L})$, covered with a thin cloth material and maintained inside the incubator (FH-1200 LED T8, HiPoint Laboratory, Taiwan) at $33 \pm 1^{\circ} \mathrm{C}$ and $60 \pm 5 \%$ relative humidity). At the pupal stage, the flour medium was sieved through $850 \mu \mathrm{m}$ and $2 \mathrm{~mm}$ mesh (ASTM E11, W.S. Tyler Industrial Group, Mentor, U.S.A.). The male and female pupae were separated using a microscope (Zhu et al., 1999) (Optika, Triace, Italy), and each pupa was introduced into a separate plastic vial (3.6 cm diameter and $6.2 \mathrm{~cm}$ height) having 5 g rice flour using an artist's brush (No. 3). The vial having the pupa was covered with a thin piece of cloth and maintained inside the incubator at $33 \pm 1{ }^{\circ} \mathrm{C}$ temperature and $60 \pm 5 \%$ relative humidity until the adults emerged. The adult moths aged 2-4 days were used in the experiments. 


\section{Wind tunnel construction}

Four cubicles (each $1.5 \mathrm{~m} \times 1.5 \mathrm{~m} \times 1.5 \mathrm{~m}$ ) with a metal frame were constructed on a cement floor. Each cubicle was housed in a separate room. Two opposite sides, top and bottom of the cubicle were covered using transparent polythene ( $25 \mathrm{~mm}$ thickness). The remaining two opposite sides were covered using an insect proof net which facilitates air circulation. A zip entry was arranged to permit the introduction of moths into the wind tunnel and recapture them following the exposure period. A domestic exhaust fan (12.0 $\mathrm{m}^{3} / \mathrm{min}$ air delivery, 1,200 rpm speed) (XFNE002, Orel Corporation Pvt Ltd, PR China) was connected to one side having the insectproof net, and close to the window of the room for easy direction of air out. This was to facilitate testing the impact of forced air flow condition on the mating status and removal of contaminated air inside the wind tunnel. The wind speed was measured by using Professional Standard Environmental meter (13/464/0, S. Brannan and Sons, Cumbria, UK).

\section{Preparation of pheromone doses}

Commercially-available pheromone ZETA was used in the study. The pheromone was kept inside the refrigerator $\left(4^{\circ} \mathrm{C}\right)$ until used. Four solutions of ZETA (10\%) were prepared using the stock solution of the commercial pheromone (Insects Ltd. Inc., Westfield, USA) diluted in hexane solution $(100 \%)$. Accordingly, $10 \%$ pheromone dose $(4.5 \mathrm{mg}$ of pheromone) was prepared mixing $4.5 \mathrm{~mL}$ of pheromone solution in $45 \mathrm{~mL}$ of hexane solution. Subsequently, the $10 \%$ pheromone doses having $1 \mathrm{mg}, 0.1 \mathrm{mg}$ and $0.05 \mathrm{mg}$ were prepared by diluting $1 \mathrm{~mL}, 0.1 \mathrm{~mL}$ and $0.05 \mathrm{~mL}$ pheromone in $10 \mathrm{~mL}, 1 \mathrm{~mL}$ and $0.5 \mathrm{~mL}$ of hexane, respectively. These four pheromone doses were added by micropipette (Labnet International, Inc, Poland) into separate glass Petri dishes and covered by individually the net material.

\section{Experimental design}

Experiments were conducted as Completely Randomized Design (CRD). The effects of pheromone dose, insect population size and the status of air movement on MD were tested. Each treatment had four replicates. All tests were conducted simultaneously under the same ambient environmental conditions ( $33 \pm 1{ }^{\circ} \mathrm{C}$ and $60 \pm 5 \%$ relative humidity).

\section{Experiment 1: Effect of pheromone dose on mating status}

The glass Petri dish having a particular pheromone dose $(0.05,0.1,1$ or $4.5 \mathrm{mg})$ was placed inside a monitoring trap (Storgard kit insect monitoring system, Trece, Inc., Adair, OK, U.S.A.) and hung to be at the middle of wind tunnel $(75 \mathrm{~cm}$ distance from top or bottom) 24 hours before introducing the adult moths. Hobo data loggers (Onset Computer Corporation, MA, U.S.A.) were placed both inside and outside of the wind tunnel to record the temperature and humidity of the environment. Three population sizes $(10,20$ or 30$)$ of $C$. cautella adults having equal number of males and females were introduced separately into the wind tunnel. The moths were maintained for 24 hours inside the wind tunnel following introduction (Ryne et al. 2001) and subsequently collected into a conical flask (250 $\mathrm{mL})$ using an aspirator, frozen $\left(-10^{\circ} \mathrm{C}\right.$ for 2 hours) inside a freezer and the female moths dissected under a microscope (Optika, Triace, Italy) to determine the presence/absence of spermatophores to ascertain the mating status (Mafra-Neto and Baker, 1996). As the spermatophores are maintained large by freezing up to $2 \mathrm{hrs}$ (Ryne et al., 2001) and thus to avoid spermatophores deteriorated with the lapse of time following mating (Drummond, 1984), the females were dissected within $2 \mathrm{hrs}$ following their removal from the wind tunnel. The mating status of moths was determined by counting the mated females. Mating status for a particular pheromone dose was conducted under natural air flow and forced air flow conditions. The effective pheromone dose ob- 
tained in this experiment 1 with natural/ forced air flow was subsequently used in the experiment 2 to find out the effective population size under that particular air flow status. Control experiments were conducted by using hexane solution (with the natural or forced air flow, as required).

\section{Experiment 2: Effect of population size on mating status}

Petri dish having the effective pheromone dose (found in experiment 1) was placed in the middle of the wind tunnel at approximately $75 \mathrm{~cm}$ distance from top or bottom of the wind tunnel by using a monitoring trap 24 hours before the introduction of moths, as practiced in the experiment 1 . Temperature and humidity inside and outside the wind tunnel were measured using Hobo data loggers (Onset Computer Corporation, MA, U.S.A). The male and female adults of $C$. cautella (aged 2-4 days), emerged individually in separate vials were introduced into the wind tunnel at three different population sizes (Table 1), maintained for 24 hours (Ryne et al., 2001), and captured from the walls of wind tunnel into a conical flask $(250 \mathrm{~mL})$ using an aspirator. Similar to the previous practice in experiment 1 , the insects were frozen (at $-10^{\circ}$ C) for 2 hours and the females dissected under a microscope (Optika, Triace, Italy) to determine the presence or absence of spermatophores. Each experiment with a particular insect population size was conducted either with the natural or forced air flow. The control experiments were conducted using hexane alone (with the natural or forced air flow, as required).

Table 1: Different population sizes of Cadra cautella used in the experiment.

\begin{tabular}{cccc}
\hline Instance & Males & Females & $\begin{array}{c}\text { Population } \\
\text { size }\end{array}$ \\
\hline 1 & 5 & 5 & 10 \\
2 & 10 & 10 & 20 \\
3 & 15 & 15 & 30 \\
\hline
\end{tabular}

\section{Statistical analysis}

The percentages of mated females were transformed using the square root of the arcsine value to accommodate the unequal variances associated with the percentage data (Ryne et al., 2001; Svensson et al., 2002; Burks and Kuenen, 2012; Trematerra et al., 2013; Toews et al., 2010; Dissanayaka et al., 2018a; Wijayaratne et al., 2019). These transformed data were analyzed using ANOVA procedures of Statistical Analysis system (SAS) (SAS Institute, 2002-2008). Mean separation of pheromone doses, population sizes and natural/ forced air flow was done by Tukey's test. The significance was tested at $\mathrm{P}=0.05$.

\section{RESULTS AND DISCUSSION Environmental conditions and moth identi- fication}

The average temperature and relative humidity inside and outside of the wind tunnels were $30 \pm 1{ }^{\circ} \mathrm{C}, 63.5 \pm 1 \%$ and $31 \pm 1^{\circ} \mathrm{C}, 64 \pm 2 \%$ respectively. The average wind speed inside the wind tunnel under forced air condition was $1.35 \mathrm{~m} / \mathrm{s}$. Under natural air flow, the average wind speed $0.2 \mathrm{~m} / \mathrm{s}$. Male pupa has two nodes close to the genital scar on the ventral side of the $8^{\text {th }}$ body segment (Zhu et al., 1999). The mated females were identified by the spermatophores in white color and located as clusters in the bursa copulatrix (Ryne et al., 2001).

\section{Effect of pheromone dose and air flow on mating status}

Overall, there was a significant effect of pheromone dose $(F=55.53 ; d f=3,27 ; P<0.0001)$ and air flow $(F=7.05 ; d f=1,27 ; P=0.0131)$ on mating status of $C$. cautella. Thus, in general, the percentage mated females was lower when the pheromone (ZETA) was present than when it was not present (in the hexane control). Under natural air flow, the percentage mated females at $4.5 \mathrm{mg}$ of ZETA (30\%) was lower than other pheromone doses (Figure 1). This decreased mated status at $4.5 \mathrm{mg}$ of ZETA means that the highest MD occurred at that dose. However, the mated female percentages $65 \%, 60 \%$ and $50 \%$ obtained at 0.05 , 
0.1 and $1 \mathrm{mg}$ of ZETA, respectively did not differ from each other. A similar pattern of mating status was observed when forced air flow was maintained as well. The mating status $(22.5 \%)$ at $4.5 \mathrm{mg}$ was lower than those at other three ZETA doses; $60 \%, 55 \%$ and $45 \%$ with $0.05,0.1$ and $1 \mathrm{mg}$, respectively. Furthermore, the three mating percentages at 0.05, 0.1 and $1 \mathrm{mg}$ of ZETA respectively did not differ from each other (Figure 2). Accordingly, the highest MD was observed in $4.5 \mathrm{mg}$

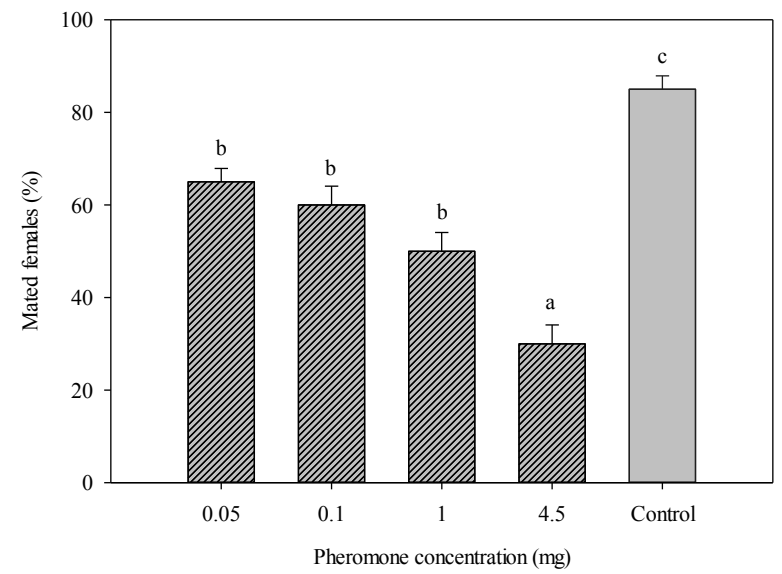

Figure 1: Percentage of mated females (mean \pm SE) at different pheromone concentrations (natural air flow condition). Means followed by the same letter are not significantly different at $P=0.05$ according to Tukey's test following ANOVA.

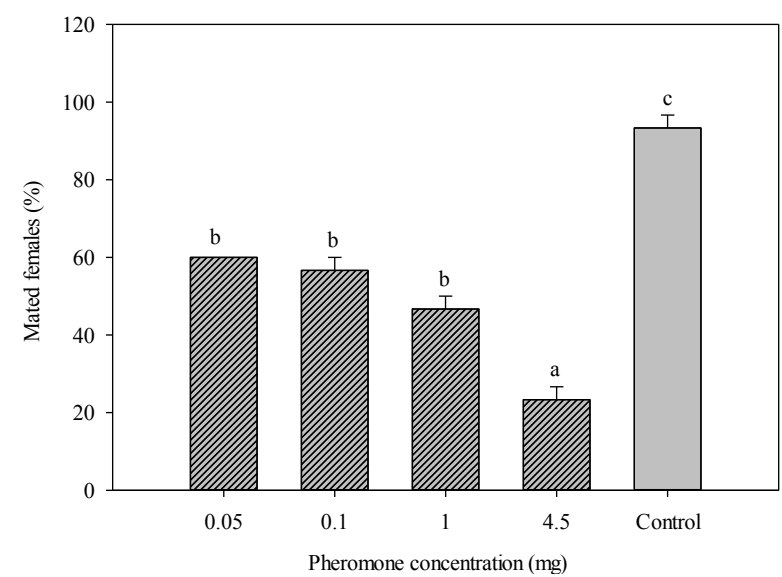

Figure 2: Percentage of mated females (mean \pm SE) at different pheromone concentrations (forced air flow condition). Means followed by the same letter are not significantly different at $P=0.05$ according to Tukey's test following ANOVA. of ZETA. The increased MD was under forced air flow condition may possibly be due to the increased dispersal of pheromone by the air flow.

The mating status is determined by the presence of spermatophores in bursa copulatrix of the female moth (Ryne et al., 2001). Similarly in the current study, spermatophores of mated females were clearly observed. The mating of Plodia interpunctella can be suppressed by 93\% by using synthetic pheromones (Ryne et al., 2001). In the current study, the highest MD was at $4.5 \mathrm{mg}$ of ZETA.

\section{Effect of insect population size on mating status}

In all the population sizes tested, mating percentages of moths exposed to ZETA were significantly lower than their respective controls both under natural and forced air flow conditions. (Figure 3 and 4). Furthermore, there was a significant effect of insect population size on mating status $(F=50.86 ; d f=5,41 ; P<0.0001)$.

Under natural air flow, the percentage of mated females at population sizes $10(5$ males +5

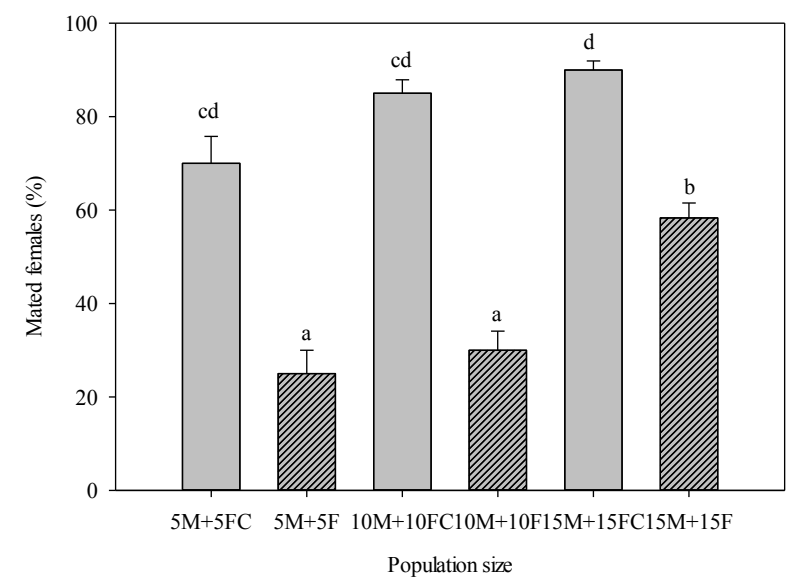

Figure 3: Percentage of mated females (mean \pm SE) at different insect population sizes (natural air flow condition). Different male (M) and female $(\mathrm{F})$ populations sizes followed by $\mathrm{C}$ indicates the mating percentages obtained in the respective control. Means followed by the same letter are not significantly different at $P=0.05$ according to Tukey's test following ANOVA. 
females) and 20 (10 males +10 females) was lower than 30 ( 15 males +15 females) (Figure $3)$. Thus, the MD was higher in low population sizes $(25 \%$ of mated females for 10 population size and $30 \%$ of mated females for 20 population size). Under forced-air flow, there was no significant difference in the percentage of mated females among the insect population sizes 10 (20\% of mated females), 20 (22.5\% of mated females) and $30(48.33 \%$ of mated females) (Figure 4). No differences in the mating status among population sizes under forced air flow condition in contrast to the alteration of mating status under natural air flow indicates that the air movement would have helped the dispersion of the pheromone throughout the space.

According to the current study, low population sizes $C$. cautella are better controlled by ZETA under natural air flow whereas all population sizes of $C$. cautella are equally controlled by ZETA under forced-air flow condition. This agrees with the previous studies on controlling of mating in low populations of $C$. cautella (Sower and Whitmer, 1977). Furthermore, another previous study indicates that

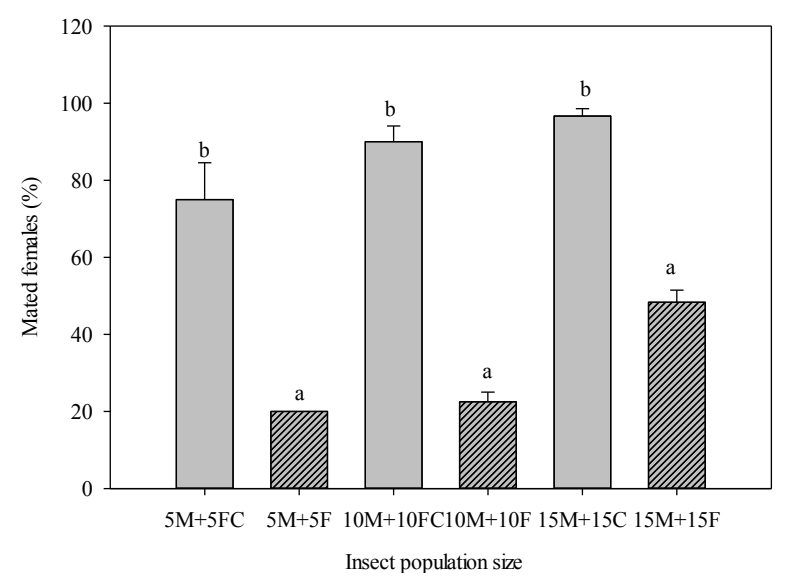

Figure 4: Percentage of mated females $($ mean \pm SE) at different insect population sizes (forced air flow condition). Different male (M) and female (F) populations sizes followed by $\mathrm{C}$ indicates the mating percentages obtained in the respective control. Means followed by the same letter are not significantly different at $\mathbf{P}=\mathbf{0 . 0 5}$ according to Tukey's test following ANOVA. the mating of C. cautella is controlled $100 \%$ in the low population densities tested (MafraNeto and Baker, 1996). In contrast, in the current research, the maximum mating percentage (approximately 58\%) of $C$. cautella moths was observed at high population size under natural air flow condition.

In general, the combination of high doses of ZETA and low population sizes of $C$. cautella ensure effective suppression of mating. This condition can be achieved when the insect population of $C$. cautella has been already controlled by using the conventional controlling methods (Hodges et al., 1984). During this experiment, the moths were aggregated in dark areas in the wind tunnel. Aggregation to specific areas increases the chance of individual moths to be mated (Ryne et al., 2001). The wind tunnel used in our experiment was simply a cubicle without modifications. However, the complexity of the wind tunnel increases the aggregation spots which may facilitate reduced mate finding (increase MD) (Ryne et al., 2001). The MD is mediated through different mechanisms: local adaptation of antennal receptors, habituation on a central level, false trail following, or camouflage of the female's pheromone plume (Carde and Minks, 1995). The MD in some other Pyralidae moths such as Plodia interpunctella has already been demonstrated (Burks and Kuenen, 2012). However, as Plodia interpunctella undergoes larval diapause (Wijayaratne and Fields, 2012), the effect of MD might be altered. This is worthy of investigation.

The current findings open up new avenues of further research on MD. Testing MD under high populations sizes that represent in actual warehouse conditions, exploration of the exact mechanism underlying MD, further testing with ZETA at different doses to maximize $\mathrm{MD}$; influence of different sex pheromone components and their ratios, botanicals and other insecticides on MD in C. cautella and other Pyralidae moths would be useful inves- 
tigations to expand the practical use of MD technology in the population monitoring and subsequent pest management programs.

\section{CONCLUSION}

Mating disruption of $C$. cautella increases at high doses $(4.5 \mathrm{mg})$ of ZETA, low population sizes $\left(5-10\right.$ moths in $\left.3.375 \mathrm{~m}^{3}\right)$ and forced air flow condition. Therefore, while being an effective monitoring tool, ZETA can effectively be used in the management strategies of $C$. cautella populations. Further exploration on different components of ZETA and incorporation them into existing pest management strategies for $C$. cautella would strengthen integrated pest management practices for this species.

\section{ACKNOWLEDGEMENTS}

The authors are grateful to Sri Lanka Council for Agricultural Research Policy (NARP/16/ RUSL/AG/01) for the financial assistance; Dr Charles Burks, Research Scientist at USDA ARS, Parlier, CA, USA for providing constructive criticisms to modify the methodology of experiments. The authors gratefully acknowledge the cooperation extended by Dr AMKR Bandara, Rajarata University of Sri Lanka by providing the space to conduct the experiment. Hexane for the initial trials were generously provided by Prof. BMR Bandara, Department of Chemistry, University of Peradeniya, Sri Lanka.

\section{REFERENCES}

Arthur FH 1996 Grain protectants: Current status and prospects for the future. J. Stored Prod. Res. 32: 293-302. doi: 10.1016/S0022-474X(96)00033-1

Arthur F, Zettler JL and Halliday WR 1988 Insecticide resistance among populations of Almond moth and Indian meal moth (Lepidoptera: Pyralidae) in stored peanuts. J. Econ. Entomol. 81: 1283-1287. doi:10.1093/jee/81.5.1283

Brady UE 1973 Isolation, identification and stimulating activity of a second component of the sex pheromone system (complex) of the female almond moth, Cadra cautella (Walker), Life Sci. Res. 13: 227-235.doi: https:// doi.org/10.1016/0024-3205(73)90021-0

Brijwani M, Subramanyam B and Flinn PW 2012 Impact of varying levels of sanitation on mortality of Tribolium castaneum eggs and adults during heat treatment of a pilot flour mill. J. Econ. Entomol. 105: 703-708. doi: 10.1603/ ec11115

Burks CS and Kuenen LPS 2012 Effect of mating disruption and lure load on the number of Plodia interpunctella (Hübner) (Lepidoptera: Pyralidae) males captured in pheromone traps. J. Stored Prod. Res. 49: 189-195. doi: 10.1016/j.jspr.2012.03.001

Campos M and Phillips TW 2014 Attract-andkill and other pheromone-based methods to suppress populations of the Indianmeal moth (Lepidoptera: Pyralidae). J. Econ. Entomol. 107: 473-480. doi: http://dx.doi.org/10.1603/ EC13451

Carde RT and Minks AK 1995 Control of moth pests by mating disruption: successes and constraints. Annu. Rev. Entomol. 40: 559-585. doi: https:// doi.org/ 10.1146/ annurev.en.40.010195.003015

Dissanayaka DMSK, Sammani AMP and Wijayaratne LKW 2018a Aggregation pheromone 4,8-dimethyldecanal and kairomone affect the orientation of Tribolium castaneum (Herbst) (Coleoptera: Tenebrionidae) adults. J. Stored Prod. Res. 79: 144-149. doi: https://doi.org/10.1016/ j.jspr.2018.07.005

Dissanayaka DMSK, Sammani AMP and Wijayaratne LKW 2018b Food oils as kairomones for trapping Tribolium castaneum (Herbst) (Coleoptera: Tenebrionidae) adults. J. Stored Prod. Res. 79: 83-88. doi: $\underline{10.1016 /}$ i.jspr.2018.09.005

Drummond BA 1984 Multiple mating and 
sperm competition in the Lepidoptera. pp. 291-370. In: Smith RL (ed.) Sperm Competition. Academic Press, London.

Eliopoulos PA, Prasodimou GZ and Pouliou AV 2010 Survival of adults and larvae of grain beetles at lethal low temperature. P. 637. In: Carvalho MO, Fields PG, Adler CS, Arthur FH, Athanassiou CG, Campbell JF, FleuratLessard F, Flinn PW, Hodges RJ, Isikber AA, Navarro S, Noyes RT, Riudavets J, Sinha KK, Thorpe GR, Timlick BH, Trematerra P, White NDG (Eds) Proceedings of the 10th International Working Conference on Stored-Product Protection (IWCSPP). 27 June-02 July, 2010, Estoril, Portugal, Julius-Kühn-Archiv, Berlin, Germany.

Evenden ML, Judd GJR and Borden JH 1999 Pheromone-mediated disruption of Choristoneura rosaceana: Is the most attractive blend really the most attractive? Entomol. Exp. Appl. 90: 37-47. doi: https://doi.org/10.1046/j.15707458.1999.00421.x

Fields PG 1992 The control of stored product insects and mites with extreme temperatures. J. Stored Prod. Res. 28: 89118. doi: https://doi.org/10.1016/0022 $-474 X(92) 90018-\mathrm{L}$

Fields PG 2012 Comparison of efficacy of methyl bromide and sulfuryl fluoride fumigations in Canadian pasta plants. Pp. 215-221. In: Navarro S, Banks HJ, Jayas DS, Bell CH, Noyes RT, Ferizli AG, Emekci M, Isikber A and Alagusundaram $\mathrm{K}$ (Eds.) Proceedings of the Ninth International Controlled Atmosphere and Fumigation in Stored Products. 15-19 October, 2012, Antalya, Turkey. ARBER Professional Congress Services, Antalya, Turkey.

Ghimire MN, Arthur FH, Myers SM and Phillips, TW 2016 Residual efficacy of deltamethrin and $\beta$-cyfluthrin against Trogoderma variabile and Tro- goderma inclusum (Coleoptera: Dermestidae). J. Stored Prod. Res. 66: 611. doi: https://doi.org/10.1016/ j.jspr.2015.12.002

Hagstrum DW and Subramanyam B 2006 Fundamentals of Stored-product Entomology. AACC International, St. Paul.

Hasaranga GDGSA, Wijayaratne LKW, Prasanna PHP, Karunarathne KGPB and Rajapakse RHS 2018 Effect of paddy variety, milling status and aeration on the progeny emergence of Sitophilus oryzae L. (Coleoptera: Curculionidae). J. Stored Prod. Res. 79: 116-122. doi: https://doi.org/10.1016/ j.jspr.2018.10.003

Hill DS 1990 Pests of stored products and their control. CBS Publishers and Distributors (Pvt.) Ltd, Belhevan Press, London.

Hodges RJ, Benton FP, Hall DR and Serodio RDS 1984 Control of Ephestia cautella (Walker) (Lepidoptera: Phyticidae) by synthetic sex pheromones in the laboratory and store. J. Stored Prod. Res. 20: 191-197. doi: https:// doi.org/10.1016/0022-474X(84)90003 $\underline{-1}$

Kuwahara Y and Casida JE 1973 Quantitative analysis of the sex pheromone of several phycitid moths by electron capture gas chromatography. J. Agric. Biol. Chemistry 37: 681-684. doi: https://

doi.org/10.1080/00021369.1973.1086 0730

Kuwahara Y, Kitamura C, Takahashi S, Hara H, Ishii S and Fukami H 1971 Sex pheromone of the almond moth and the Indian meal moth: cis-9, trans- 12tetradecadienyl acetate. Sci. 171: 801802 doi: 10.1126/ science.171.3973.801

Mafra-Neto A and Baker TC 1996 Timed, metered sprays of pheromone disrupt mating of Cadra cautella (Lepidoptera: Pyralidae). J. Agric. En- 
tomol. 13: 149-168. doi: http:// scentsoc.org/Volumes/JAE/ v13/2/00132149.pdf

Opit GP, Phillips TW, Aikins MJ and Hasan MM 2012 Phosphine resistance in Tribolium castaneum and Rhyzopertha dominica from stored wheat in Oklahoma. J. Econ. Entomol. 105: 11071114. doi: https://doi.org/10.1603/ EC12064

Phillips TW 1997 Semiochemicals of Storedproduct Insects: Research and applications. J. Stored Prod. Res. 33: 1730. doi: https://doi.org/10.1016/S0022 -474X(96)00039-2

Phillips TW and Throne JE 2010 Biorational approaches to managing stored product insects. Annu. Rev. Entomol. 55: 375-397. doi: 10.1146/ annurev.ento.54.110807.090451

Read JS and Beevor PS 1976 Analytical studies on the sex pheromone complex of Ephestia cautella (Walker) (Lepidoptera: Phycitidae). J. Stored Prod. Res. 12: 55-57. doi: https:// doi.org/10.1016/0022-474X(76)90023 $-0$

Read JS and Haines CP 1976 The function of the female sex pheromones of Ephestia cautella (Walker) (Lepidoptera, Phycitidae). J. Stored Prod. Res. 12: 49-53. doi: https:// doi.org/10.1016/0022-474X(76)90022 $\underline{-9}$

Ridley AW, Burrill PR, Cook CC and Daglish GJ 2011 Phosphine fumigation of silo bags. J. Stored Prod. Res. 47: 349 $-356$. doi:org/10.1016/ j.jspr.2011.06.001

Ryne C, Svensson GP and Lofstedt C 2001 Mating disruption of Plodia interpunctella in small-scale plots: Effects of pheromone blend, emission rates and population density. J. Chemical Ecol. 27: 2109-2124. doi: https:// link.springer.com/ article/ 10.1023/ A\%3A1012251106037

Ryne C, Ekeberg M, Jonzen N, Oehlschlager
C, Lofstedt C and Anderbrant O 2006 Reduction in an almond moth Ephestia cautella (Lepidoptera: Pyralidae) population by means of mating disruption. Pest Manage. Sci. 62: 912-918. doi: https://doi.org/10.1002/ps.1256

Sanon A, Dabire-Binso LC and Ba NM 2011 Triple-bagging of cowpeas with high density polyethylene bags to control the cowpea beetle Callosobruchus maculatus F. (Coleoptera: Bruchidae). J. Stored Prod. Res. 47: 210-215. doi: https://doi.org/ j.jspr.2011.02.003

SAS Institute 2002-2008 The SAS system for windows, Release 9.1. Statistical Analysis System Institute, Cary, NC, USA.

Sauer AE and Karg G 1998 Variables affecting pheromone concentration in vineyards treated for mating disruption of grape vine moth Lobesia botrana. J. Chem. Ecol. 24: 289-302. doi: https:// doi.org/10.1023/A:102253242

Sower LL and Whitmer GP 1977 Population growth and mating success of Indian meal moths and almond moths in the presence of synthetic sex pheromone. Environ. Entomol. 6: 17-20. doi: https://doi.org/10.1093/ee/6.1.17

Staten RT, Flint HM, Weddle RC, Hernandez E and Yamamoto A 1987 Pink bollworm (Lepidoptera: Gelechiidae): Large-scale field trials with a high-rate gossyplure formulation. J. Econ. Entomol. 80: 1267-1271. doi: https:// doi.org/10.1093/jee/80.6.1267

Svensson GP, Ryne C and Lofstedt C 2002 Heritable variation of sex pheromone composition and the potential for evolution of resistance to pheromonebased control of the Indian meal moth, Plodia interpunctella. J. Chem. Ecol. 28: 1447-1461. doi: https:// doi.org/10.1023/A:1016204820674

Thorpe KW, Mastro VC, Leonard DS, Leonhardt BA, Mclane W, Reardon RC and Talley SE 1999 Comparative efficiency 
of two controlled-release gypsy moth mating disruption formulations. Entomol. Exp. Appl. 90: 267-277. doi: https://doi.org/10.1046/j.15707458.1999.00447.x

Toews MD, Campbell JF and Arthur FH 2010 The presence of flour affects the efficacy of aerosolized insecticides used to treat the red flour beetle, Tribolium castaneum. J. Insect Sci. 10 (196). doi: https://doi.org/10.1673/031.010.19601

Trematerra P 2012 Advances in the use of pheromones for stored-product protection. J. Pest Sci. 85: 285-299. doi: 10.1007/s10340-011-0407-9

Trematerra P, Athanassiou CG, Sciarretta A, Kavallieratos NG and Buchelos CT 2013 Efficacy of the auto-confusion system for mating disruption of Ephestia kuehniella (Zeller) and Plodia interpunctella (Hübner). J. Stored Prod. Res. 55: 90-98. doi: $\underline{10.1016 /}$ j.jspr.2013.07.001

Vick KW, Coffelt JA, Mankin RW and Soderstrom EL 1981 Recent developments in the use of pheromones to monitor Plodia interpunctella and Ephestia cautella. pp. 19-28. In Mitchell, E.R. (ed.) Management of insect pests with semiochemicals; concepts and practice. New York, Plenum Press.

Wijayaratne LKW and Fields PG 2010 Effect of methoprene on the heat tolerance and cold tolerance of Tribolium castaneum (Herbst) (Coleoptera: Tenebrionidae). J. Stored Prod. Res. 46: 166173. doi: https://doi.org/10.1016/ j.jspr.2010.04.001

Wijayaratne LKW and Fields PG 2012. Effects of rearing conditions, geographical origin, and selection on larval diapause in the Indianmeal moth, Plodia interpunctella. J. Insect Sci. 12: 1-10. doi: 10.1673/031.012.11901

Wijayaratne LKW and Rajapakse RHS 2018 Effects of spinosad on the heat tolerance and cold tolerance of Sitophilus oryzae L. (Coleoptera: Curculionidae) and Rhyzopertha dominica F. (Coleoptera: Bostrichidae). J. Stored Prod. Res. 77: 84-88. doi: https:// doi.org/10.1016/j.jspr.2018.03.001

Wijayaratne LKW, Arthur FH and Whyard S 2018 Methoprene and control of storedproduct insects. J. Stored Prod. Res. 76: 161-169. doi: https://doi.org/10.1016/ j.jspr.2016.09.001

Wijayaratne LKW, Dissanayaka DMSK and Sammani AMP 2019 Variation in Rhyzopertha dominica (F.) (Coleoptera: Bostrychidae) progeny adult emergence in different animal feed stored under ventilated and non-ventilated conditions. J. Stored Prod. Res. 84 (101516). doi: https://doi.org/10.1016/ j.jspr.2019.101516

Wijayaratne LKW, Fernando MD and Palipane KB 2009 Control of insect pests under ware-house conditions using smoke generated from partial combustion of rice (paddy) husk. J. Natn. Sci. Foundation Sri Lanka. 37: 125-134. doi: 10.4038/jnsfsr.v37i2.1069

Wijayaratne LKW, Fields PG and Arthur FH 2012a Effect of methoprene on the progeny production of Tribolium castaneum (Coleoptera: Tenebrionidae). Pest Management Sci. 68: 217-224. doi: 10.1002/ ps. 2247

Wijayaratne LKW, Fields PG and Arthur FH 2012b Residual efficacy of methoprene for control of Tribolium castaneum (Coleoptera: Tenebrionidae) larvae at different temperatures on varnished wood, concrete, and wheat. J. Econ. Entomol. 105: 718-725. doi: org/10.1603/ EC11375

Zhu JW, Ryne C, Unelius CR, Valeur PG and Lofstedt C 1999 Reidentification of the females sex pheromone of the Indian meal moth, Plodia interpunctella: Evidence for a four-component pheromone blend. Entomol. Exp. Appl. 92: 137146. doi: https://doi.org/10.1046/j.15707458.1999.00533.x 